\title{
UJI AKTIVITAS ANTIBAKTERI EKSTRAK DAUN BELIMBING HUTAN (CNESTIS PALALA (LOUR)MERR)
}

\author{
Ferdiand George Sarung Allo*, Dewi Rahmawati, Adam M Ramadhan \\ Laboratorium Penelitian dan Pengembangan FARMAKA TROPIS, Fakultas \\ Farmasi Universitas Mulawarman, Samarinda, Kalimantan Timur \\ *email:ferdiangeorge@gmail.com
}

\begin{abstract}
ABSTRAK
Tanaman belimbing hutan merupakan tanaman yang secara empiris digunakan untuk meredakan sakit perut dan juga untuk menyembuhkan luka yang disertai infeksi. Penelitian ini bertujuan untuk mengidentifikasi senyawa metabolit sekunder serta mengetahui aktivitas antibakteri dari ekstrak daun belimbing hutan (Cnestis Palala(Lour)Merr) terhadap beberapa bakteri uji. Sampel dikumpulkan kemudian dimaserasi menggunakan pelarut metanol. Identifikasi senyawa metabolit sekunder dilakukan menggunakan uji kualitatif dengan mereaksikan sampel dengan beberapa reagen. Pengujian aktivitas antibakteri dilakukan dengan menggunakan metode difusi agar pada konsentrasi 10\%, 20\%, 30\%, 40\% dan 50\%. Data hasil identifikasi metabolit sekunder dianalisis secara kualitatif dengan melihat adanya perubahan warna. Hasil identifikasi golongan senyawa metabolit sekunder pada ekstrak positif terdapat senyawa flavonoid, fenol dan tannin. Data hasil pengujian antibakteri dianalisis dengan mengukur zona bening yang terbentuk disekitar paper disc. Hasil pengujian antibakteri menunjukkan bahwa ekstrak daun belimbing hutan memiliki aktivitas sebagai antibakteri. Konsentrasi terbaik ekstrak daun belimbing hutan dalam membunuh bakteri yaitu 50\% dengan rata-rata diameter zona bunuh Escherichia coli $(10.40 \mathrm{~mm})$, Salmonella thyposa $(9.77 \mathrm{~mm})$, Staphylococcus aureus (10.17 mm), dan Bacillus subtilis $(9.67 \mathrm{~mm})$.
\end{abstract}

Kata kunci : Belimbing Hutan, Cnestis palala (Lour) Merr, Antibakteri.

\section{PENDAHULUAN}

Mikroba patogen merupakan mikroba yang dapat menyebabkan penyakit pada tubuh, contohnya penyakit yang disebabkan oleh mikroba patogen yaitu infeksi kulit, meningitis dan candiasis. Jika mikroba tersebut masuk ke dalam saluran sistematik maka dapat menyebabkan penyebaran mikroba di dalam tubuh dan dapat menimbulkan penyakit yang dapat berujung kematian. Biasanya digunakan antibiotik untuk mengobati penyakit yang disebabkan oleh mikroba 
tersebut. Semakin meningkatnya infeksi maka penggunaan antibiotik juga akan semakin meningkat, hal ini dapat menyebabkan besarnya peluang resistensi oleh masyarakat terhadap penggunaan antibiotik. Sehingga dibutuhkan bahan-bahan alam yang dapat membunuh bakteri-bakteri tersebut dengan meminimalisir resistensi maupun efek samping lainnya.

Belimbing hutan (Cnestis Palala.(Lour)Merr) merupakan tanaman yang sangat berkhasiat untuk pengobatan, di Indonesia sendiri tanaman ini tidak begitu dikenal hanya sebagian daerah saja yang biasa memanfaatkan tanaman ini sebagai alternatif pengobatan salah satunya daerah Kalimantan Timur. Dinegara lain contohnya Malaysia, rebusan akar belimbing hutan diminum untuk mengobati malaria, meredakan sakit perut, menormalkan buang air kecil, mengatasi keseleo dan menyembuhkan luka yang diikuti dengan terjadinya infeksi.

Penelitian ini bertujuan untuk mengidentifikasi senyawa metabolit sekunder serta mengetahui aktivitas antibakteri dari ekstrak daun belimbing hutan (Cnestis Palala(Lour)Merr) terhadap beberapa bakteri uji, diantaranya yaitu Escherichia coli, Salmonella thypi, Bacillus Subtilis, dan Staphylococcus aureus.

\section{METODE PENELITIAN}

\section{Bahan}

Bahan yang diteliti adalah daun belimbing hutan (Cnestis Palala(Lour)Merr) yang diperoleh dari kawasan hutan kalimantan tepatnya di daerah Kutai Timur. Pelarut yang digunakan pada proses ekstraksi adalah metanol. Mikroba uji yang digunakan adalah Escherchia coli, Salmonella thypi, Bacillus subtilis dan Staphylococcus aureus. Medium yang digunakan adalah Nutrient Agar (NA). $\mathrm{NaCl}$ 0,9\% sebagai media pensuspensi bakteri. Aquades digunakan untuk melarutkan ekstrak. Paper disc atau kertas saring (Whatman no.42) sebagai penyerap ekstrak untuk uji antibakteri.

\section{Peralatan}

Peralatan yang digunakan dalam penelitian ini antara lain serangkaian alat rotary evaporator, waterbath, cawan porselin, tabung reaksi, rak tabung reaksi, timbangan analitik, cawan petri, LAF (Laminar Air Flow), spoid, inkubator, 
autoklaf, labu ukur, batang pengaduk, Erlenmeyer, hote plate dan alat penunjang lainnya.

\section{Prosedur Penelitian}

\section{Pengambilan Sampel}

Daun belimbing hutan yang akan digunakan dalam penelitian ini diambil dari tanaman utuh yang kemudian daun tersebut dicuci dengan air mengalir untuk menghilangkan kotoran pada daun. Setelah sampel dicuci dilakukan pemotongan atau perajangan sampel. Dan selanjutnya sampel dikeringkan dengan menggunakan oven pada suhu $55^{\circ} \mathrm{C}$. Kemudian ditimbang berat simplisia kering daun belimbing hutan yang telah dihasilkan.

\section{Ekstraksi}

Simplisia daun belimbing hutan yang telah diperoleh sebanyak 2000 gram diekstraksi menggunakan pelarut metanol dengan metode maserasi selama $2 \times 24$ jam. Ekstrak metanol yang diperoleh kemudian disaring dan dilakukan pemekatan ekstrak menggunakan rotary evaporator. Setelah itu diuapkan hingga diperoleh ekstrak kering. Kemudian ditimbang ekstrak kering yang telah diperoleh.

\section{Identifikasi Metabolit Sekunder}

\section{Uji Alkaloid}

Ekstrak ditambahkan $5 \mathrm{~mL} \mathrm{HCl} 2 \mathrm{~N}$. Larutan kemudian dibagi kedalam tiga tabung reaksi. Tabung 1 ditambahkan 4-5 tetes larutan Dragendorff, tabung 2 ditambahkan 4-5 tetes larutan Mayer dan tabung 3 ditambahkan 4-5 tetes pereaksi Wagner. Reaksi positif bila terbentuk endapan jingga pada tabung 1, reaksi positif bila terbentuk endapan putih pada tabung 2 dan reaksi positif juga dipastikan bila terbentuk endapan coklat pada tabung 3 (Simaremare, 2014).

\section{Uji Flavonoid}

Ekstrak ditambahkan dengan air panas, didihkan selama 5 menit, kemudian disaring. Ditambahkan 0,05 mg serbuk $\mathrm{Mg}$ dan $1 \mathrm{~mL} \mathrm{HCl}$ pekat, kemudian dikocok kuat-kuat. Uji positif ditunjukkan dengan terbentuknya warna merah, kuning atau jingga (Wijaya, 2014).

\section{Uji Fenolik}

Ekstrak ditambahkan dengan 1mL larutan Fe(III) klorida 1\%. Jika terbentuk 
warna biru tua, biru kehitaman atau hitam kehijauan menunjukkan adanya senyawa fenolik (Simaremare, 2014).

\section{Uji Tanin}

Ekstrak ditambahkan dengan 1 mL larutan Fe(III) klorida 10\%. Jika terbentuk warna biru tua, biru kehitaman atau hitam kehijauan menunjukkan adanya senyawa dan tanin (Simaremare, 2014).

\section{Uji Steroid dan Triterpenoid}

Sebanyak 1 gram ekstrak ditambahkan asam asetat glasial sebanyak 10 tetes dan asams sulfat pekat sebanyak 2 tetes. Larutan dikocok perlahan dan dibiarkan selama beberapa menit. Adanya steroid ditunjukan oleh warna biru atau hijau, sedangkan triterpenoid memberikan warna merah atau ungu (Baud, 2014).

\section{Uji Saponin}

Ekstrak dimasukkan ke dalam tabung reaksi, kemudian ditambahkan air panas lalu didinginkan, kemudian dikocok kuat-kuat selama 10 detik lalu ditambahkan 1 tetes $\mathrm{HCl} 2 \mathrm{~N}$. Uji positif ditunjukkan dengan terbentuknya buih yang stabil setinggi 1-10 cm selama tidak kurang dari 10 menit (Baud, 2014)

\section{Pengujian Aktivitas Antibakteri}

Pengujian aktivitas antibakteri dilakukan dengan membuat medium NA terlebih dahulu. Kemudian dilakukan proses sterilisasi alat dan bahan dengan menggunakan autoklaf pada suhu $121^{\circ} \mathrm{C}$ selama 15 menit. Selanjutnya dilakukan pembuatan biakan bakteri dengan menanam bakteri uji diatas permukaan medium NA dengan menggunakan metode agar miring yang telah memadat dalam tabung reaksi, yang kemudian diinkubasi dengan menggunakan inkubator pada suhu $37^{\circ} \mathrm{C}$ selama $1 \times 24$ jam. Setelah diinkubasi dilanjutkan dengan pembuatan suspensi bakteri menggunakan $\mathrm{NaCl}$ 0,9\% hingga diperoleh pengenceran 1:40.

Pengujian aktivitas antibakteri ekstrak daun belimbing hutan dilakukan dengan metode difusi agar dengan menggunakan medium NA. Sebanyak 0,02 $\mathrm{ml}$ suspensi bakteri dengan pengenceran 1:40 dan $10 \mathrm{~mL}$ medium NA dimasukkan ke dalam cawan petri steril, kemudian dihomogenkan dan setelah itu ditunggu hingga medium padat. Rendam paperdisc di dalam masing-masing larutan uji dengan berbagai konsentrasi $(10 \%, 20 \%, 30 \%, 40 \%$ dan 50\%) selama 15 menit. Setelah 15 menit diletakkan di atas 
permukaan medium NA yang telah padat, dan diinkubasi pada suhu $37^{\circ} \mathrm{C}$ selama $1 \times 24$ jam. Kontrol negatif menggunakan paperdisc yang telah dicelupkan di dalam aquades.

\section{HASIL DAN PEMBAHASAN}

\section{Identifikasi Metabolit Sekunder}

Metabolit sekunder adalah suatu molekul atau produk metabolik yang dihasilkan oleh proses metabolisme sekunder mikroorganisme dimana produk metabolik tersebut bukan merupakan kebutuhan pokok mikroorganisme untuk hidup dan tumbuh. Meskipun tidak dibutuhkan untuk pertumbuhan, namun metabolit sekunder dapat juga berfungsi sebagai nutrisi darurat untuk bertahan hidup (Pratiwi, 2008).

Berdasarkan hasil identifikasi golongan senyawa metabolit sekunder terhadap ekstrak daun belimbing hutan diperoleh hasil bahwa terdeteksinya beberapa golongan senyawa metabolit sekunder, diantaranya yaitu flavanoid, fenolik, dan tanin. Hasil uji metabolit sekunder dapat dilihat pada Tabel 1.

Tabel 1. Data Identifikasi Golongan Senyawa Metabolit Sekunder Daun Belimbing Hutan

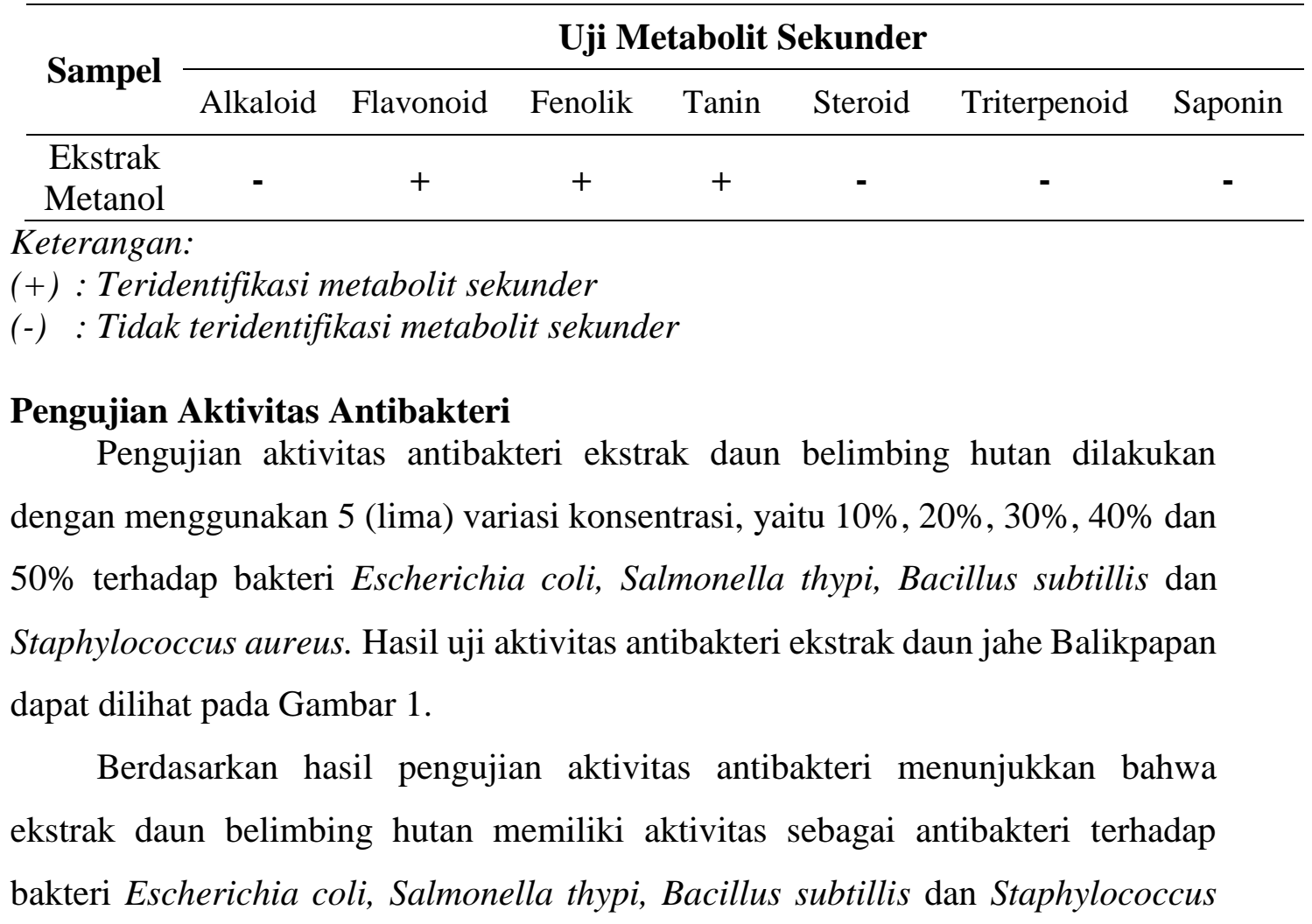


aureus. Hal ini ditandai dengan terbentuknya zona bunuh disekitar paperdisc. Pada kontrol negatif yang merupakan aquades tidak terbentuk zona bunuh ataupun zona hambat, sehingga dapat diketahui bahwa pelarut yang digunakan tidak mempengaruhi aktivitas antibakteri. Hal ini membuktikan bahwa aktivitas antibakteri yang terbentuk merupakan aktivitas dari ekstrak daun belimbing hutan.

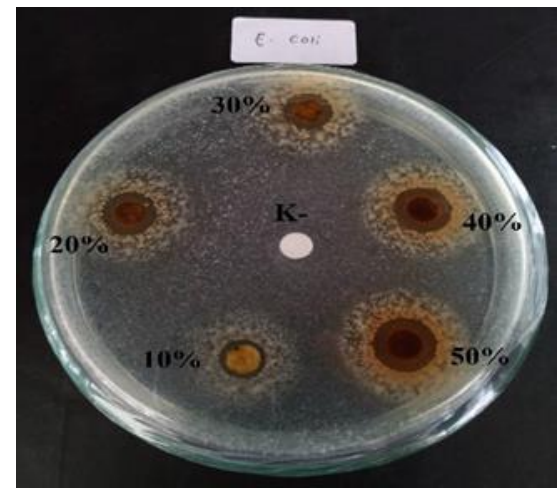

A

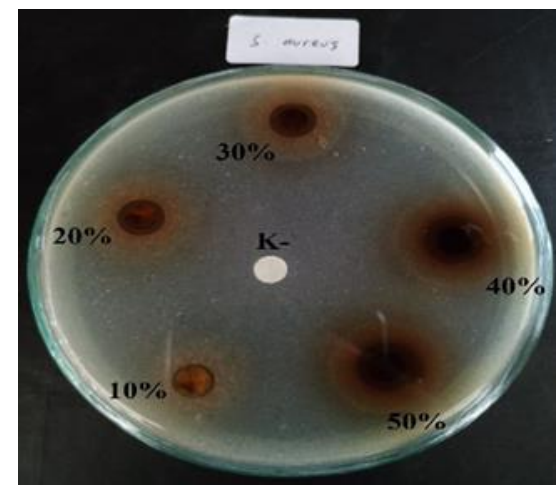

C

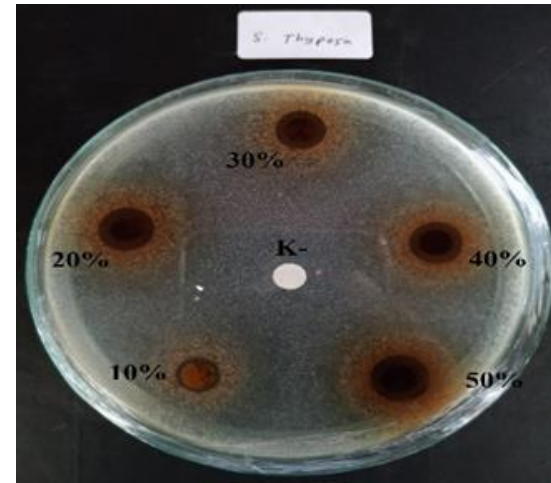

B



D

Gambar 1. Uji Aktivitas Antibakteri Ekstrak Daun Belimbing Hutan Terhadap Bakteri Escherichia coli (A), Salmonella thypi (B), Staphylococcus aureus (C) dan Bacillus subtillis (D)

Hasil pengujian aktivitas antibakteri ekstrak daun belimbing hutan menunjukkan diameter zona bunuh yang berbeda-beda pada tiap konsentrasi terhadap beberapa bakteri seperti yang dapat dilihat pada Tabel 2. 
Tabel 2. Diameter Zona Bunuh Ekstrak Daun Belimbing Hutan

\begin{tabular}{cccccc}
\hline \multirow{2}{*}{ Sampel } & Konsentrasi & \multicolumn{4}{c}{ Rerata Diameter Zona Bunuh (mm) } \\
\cline { 3 - 6 } & $(\boldsymbol{\%})$ & $\begin{array}{c}\text { Eschericia } \\
\text { coli }\end{array}$ & $\begin{array}{c}\text { Salmonella } \\
\text { thypi }\end{array}$ & $\begin{array}{c}\text { Staphylococcus } \\
\text { aureus }\end{array}$ & $\begin{array}{c}\text { Bacillus } \\
\text { subtillis }\end{array}$ \\
\hline \multirow{2}{*}{ Ekstrak Daun } & $10 \%$ & 6.54 & 6.60 & 6.87 & 6.48 \\
Jahe Balikpapan & $20 \%$ & 7.67 & 8.0 & 7.66 & 7.09 \\
(Etlingera & $30 \%$ & 7.85 & 8.07 & 8.49 & 7.70 \\
balikpapanensis) & $40 \%$ & 9.38 & 9.21 & 9.97 & 9.45 \\
Kontrol Negatif & $50 \%$ & 10.40 & 9.77 & 10.17 & 9.67 \\
(Aquades) & 0 & 0 & 0 & 0 & 0 \\
\hline
\end{tabular}

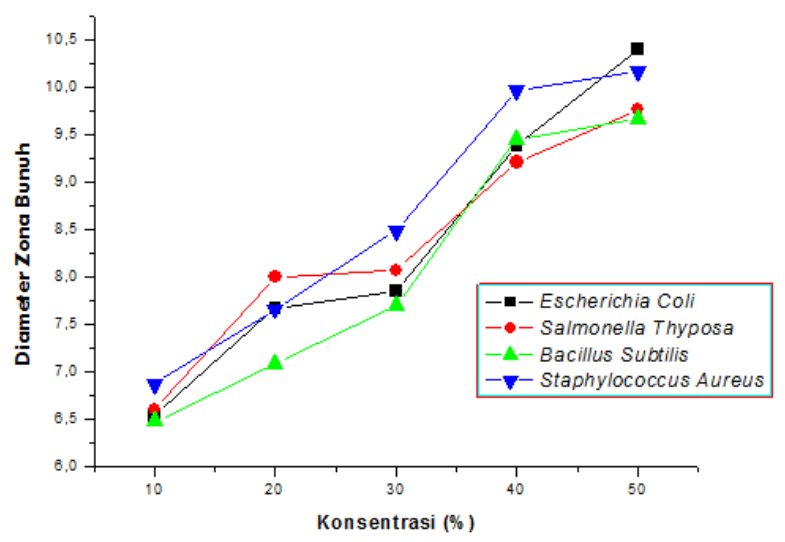

Gambar 2. Grafik Diameter Zona Bunuh Ekstrak Daun Belimbing Hutan terhadap bakteri Escherichia coli, Salmonella thypi, Staphylococcus aureus dan Bacillus subtillis.

Tabel 2 dan Gambar 2 menunjukkan bahwa terdapat aktivitas antibakteri dari ekstrak daun belimbing hutan dengan berbagai konsentrasi terhadap berbagai bakteri. Dimana semakin meningkat konsentrasi ekstrak maka semakin meningkat pula aktivitas sebagai antibakteri. Hal ini ditunjukkan dengan meningkatnya grafik diameter zona bunuh ekstrak daun belimbing hutan. Konsentrasi terbaik ekstrak daun belimbing hutan merupakan konsentrasi yang memberikan aktivitas antibakteri paling besar dalam membunuh pertumbuhan bakteri yang ditunjukkan dengan adanya zona bunuh. 
Gambar 2. menunjukkan bahwa konsentrasi terbaik dari ekstrak daun belimbing hutan dapat membunuh bakteri Escherichia coli, Salmonella thypi, Staphylococcus aureus dan Bacillus subtillis adalah 50\%.

Aktivitas antibakteri pada ekstrak daun belimbing hutan dimungkinkan karena adanya kandungan golongan senyawa metabolit sekunder yang dapat berkhasiat sebagai antibakteri, seperti fenolik dan tanin.

\section{KESIMPULAN}

Berdasarkan penelitian yang telah dilakukan, dapat diperoleh kesimpulan sebagai berikut:

1. Ekstrak daun belimbing hutan (Cnestis palala(Lour)Merr) positif mengandung senyawa golongan metabolit sekunder berupa fenolik, flavanoid dan tanin.

2. Ekstrak daun belimbing hutan (Cnestis palala(Lour)Merr) memiliki aktivitas sebagai antibakteri terhadap bakteri Escherichia coli, Salmonella thypi, Staphylococcus aureus dan Bacillus subtillis.

3. Konsentrasi terbaik ekstrak daun belimbing hutan dalam membunuh pertumbuhan bakteri Escherichia coli, Salmonella thypi, Staphylococcus aureus dan Bacillus subtillis adalah 50\%.

\section{DAFTAR PUSTAKA}

Baud, Grace S,Meiske S. Sangi. Dan Harry S.J. Koleangan. 2014. Analisis Senyawa Metabolit Sekunder Dan Uji Toksisitas Ekstrak Etanol Batang Tanaman Patah Tulang (Euphorbia tirucalli L.) Dengan Metode Brine Shrimp Lethality Test (BSLT). Jurnal Ilmiah Sains. Vol. 14, No.2.

Pratiwi, Sylvia. 2008. Mikrobiologi Farmasi. EGC. Jakarta.

Simaremare, Eva Susanty. 2014. Skrining Fitokimia Ekstrak Etanol Daun Gatal (Laportea decumana (Roxb.) Wedd). Jurnal Pharmacy. Vol. 11, No.1.

Wijaya, Dwi Putra, Jessy E. Paendong, Jemmy Abidjulu. 2014. Skrining Fitokimia dan Uji Aktivitas Antioksidan dari Daun Nasi (Phrynium capitatum) dengan Metode DPPH (1,1-difenil-2-pikrilhidrazil). Jurnal MIPA UNSRAT Online. 3(1): $11-15$ 